\title{
Consulta por masa escrotal: lesiones epidimarias
}

\author{
Serrano Frago P, Medrano Llorente P, Borque Fernando Á, Pascual Llorente M*, Allue López M. \\ Servicios de Urología y *Anatomía Patológica Hospital Universitario Miguel Server. Zaragoza.
}

Actas Urol Esp. 2007;31(4):420-422

\section{RESUMEN}

CONSULTA POR MASA ESCROTAL: LESIONES EPIDIMARIAS

Con esta revisión pretendemos actualizar los conocimientos acerca de los tumores de epidídimo, describiendo problemas en el diagnostico y tratamiento.

Presentamos el caso de un paciente de 39 años que consulta por masa testicular izquierda, ante la duda ecográfica de tumor se realizó resonancia nuclear magnética que apuntaba hacia lesión tumoral. Se realizó exéresis de la lesión vía inguinal y el diagnóstico anatomopatológico fue de tumor adenomatoide.

Dada las escasas series que aparecen en la literatura, y siendo los comentarios de estos tumores acerca de casos aislados, creemos oportuno exponer las características de este caso ilustrado iconográficamente para valorar las características diagnosticas y actitud terapéutica para poder compararlas con otros casos.

Palabras clave: Epidídimo. Adenomatoide. Lesiones tumorales paratesticulares.

\section{ABSTRACT}

\section{CONSULTS BY SCROTUM MASS: EPIDIDYMO LESIONS}

In this review we try to update the knowledge about the tumors of epididymis, describing problems in diagnosis and treatment.

We present a case of a 39 years old patient who consults by left testicular mass, before the sonogarphy suspect of tumor was made magnetic resonance imaging, wich aimed towards tumorlike injury. Excision of the injury via inguinal was made and the pathologic diagnosis was of adenomatoid tumor.

Owing to the few series that appear in literature, and being the commentaries of these tumors about isolated cases, we expose the characteristics of this illustrated case to value the characteristics in diagnosis and treatment to compare them with other cases.

Keywords: Epidídimo. Adenomatoid. Paratestis mass.

$\mathrm{L}$ as lesiones sólidas escrotales extratesticulares son poco frecuentes y en su mayoría benignas, los tumores del epidídimo representan menos del $5 \%$ de las neoplasias intraescrotales ${ }^{1}$.

Dentro de los tumores de tejidos paratesticulares los más frecuentes son los tumores adenomatoides alrededor del 30\% presentándose en el epidídimo, túnicas testiculares y en rara ocasión en el cordón espermático ${ }^{2}$.

Presentamos un caso de tumor adenomatoide de epidídimo diagnosticado histológicamente tras realizarse revisión quirúrgica por sospecha de lesión tumoral mediante resonancia nuclear magnética.

\section{CASO CLINICO}

Varón de 39 años con el único antecedente de estar apendicectomizado. Acude a nuestra consulta por palparse una masa a nivel de hemiescroto izquierdo que provoca dolor leve en la zona, sin presentar ningún episodio infectivo, ni traumático previo, ni clínica acompañante a otros niveles. 
A la exploración se palpa una tumoración en cola de epidídimo izquierdo de aproximadamente $2 \mathrm{~cm}$. de diámetro compatible con quiste de cola epididimaria, no se evidencia adherencia del mismo a estructuras adyacentes y produce minima clínica álgica al paciente.

Las analíticas sanguíneas se encontraban dentro de rangos normales y el estudio ecográfico mostraba una imagen de $16,5 \mathrm{~mm}$ por 14,0 $\mathrm{mm}$ de tamaño que dependía de cola de epidídimo con engrosamiento de la misma o acumulo de grasa, por lo que se recomienda por parte del radiólogo realización de resonancia nuclear magnética para descartar la existencia de un tumor o metástasis.

La resonancia evidenciaba una lesión bien definida a nivel de polo inferior de testículo izquierdo. Aparecía como una lesión redondeada ipsointensa en $\mathrm{T} 1$ con halo hipointenso y centro más hiperintenso en T2, realce posterior, contraste en el plano coronal, potenciado en $\mathrm{T} 1$ sugestivo de proceso tumoral (Fig. 1).

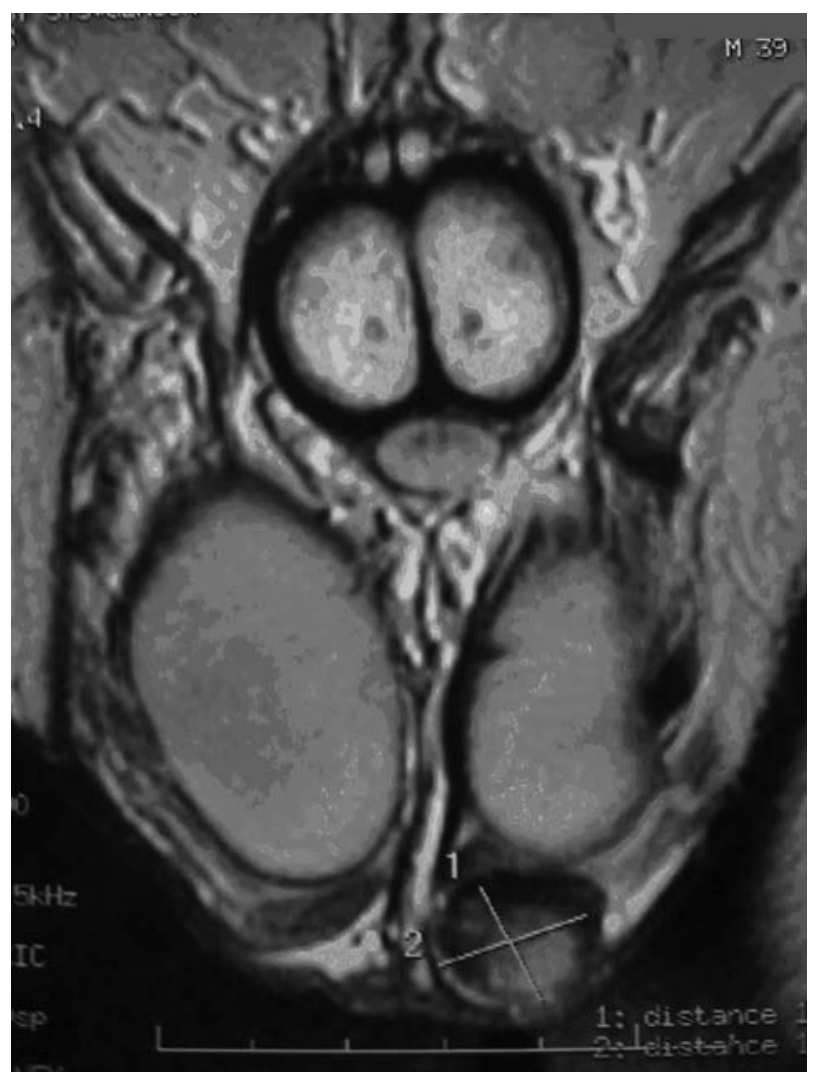

FIGURA 1. Lesión bien delimitada en polo inferior de testiculo izquierdo.
Ante la sospecha de tumor a nivel de epidídimo se realizó una revisión quirúrgica vía inguinal planteando escisión de la lesión previo clampaje del pedículo testicular.

Intraoperatoriamente se comprobó que la lesión era redondeada bien delimitada sin adherencia a túnicas testiculares y dependía de cola de epidídimo por una estrecha zona por lo que se extirpó sin la exéresis total del epidídimo.

Macroscópicamente se apreciaba un nódulo redondeado de aproximadamente $2 \mathrm{~cm}$ de diámetro, de aspecto amarillento al corte (Fig. 2).

En el estudio microscópico no se observaban lesiones malignas, sino células epiteliales con presencia de vacuolas de diverso tamaño en su citoplasma llegando al diagnóstico de tumor adenomatoide de epidídimo (Fig. 3).

\section{DISCUSIÓN}

El tumor adenomatoide, de origen mesotelial, es la neoplasia benigna más frecuente del epidídimo seguida del cistoadenoma papilar. La mayoría se presenta en la tercera y cuarta década de la vida, de forma asintomática y se descubren en el examen de rutina, en ocasiones puede provocar molestias leves asociadas con el nódulo. La mayoría de los tumores adenomatoides aparecen en la cabeza del epidídimo pero otros sitios son túnica vaginal y albugínea, cordón espermático y testículo ${ }^{3}$.

En el examen macroscópico son lesiones sólidas, redondeadas bien delimitadas con superficie al corte de aspecto fibroso. Histológicamente presentan células epiteliales y estroma fibroso, con una serie de espacios más o menos irregulares; es frecuente la aparición de vacuolas de diferentes tamaños en el citoplasma de las células epiteliales. ${ }^{4}$

Se desconoce el origen de estos tumores y se han postulado diversos orígenes mesonéfrico, mülleriano, celómico o mesotelial, este último el más aceptado ${ }^{5}$.

El diagnóstico de sospecha es clínico, el método utilizado es la ecografía por su rentabilidad sin presentar imágenes patognomónicas y con amplia variedad de las presentaciones sonográficas. Para realizar diagnósticos diferenciales en cuanto a otras patologias que aparecen como masas extratesticulares escrotales, se puede uti- 


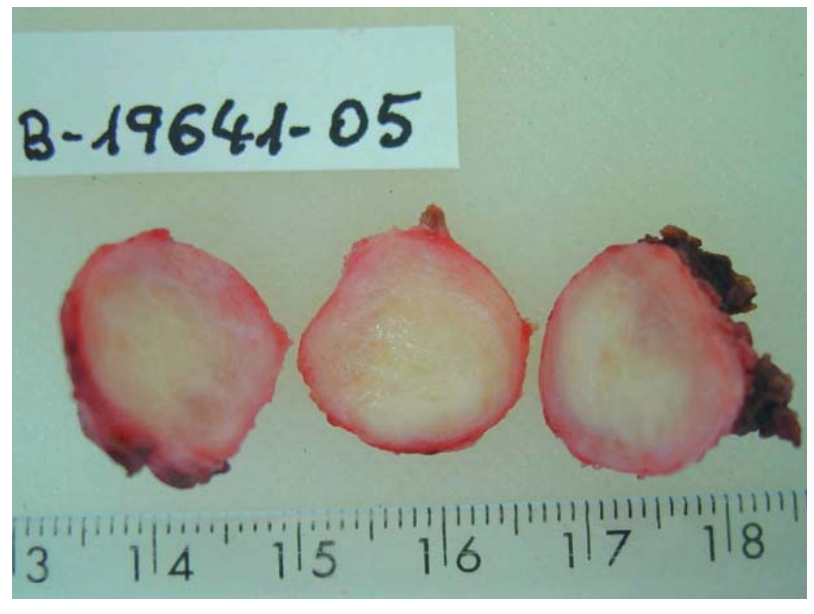

FIGURA 2. Nódulo sólido bien delimitado.

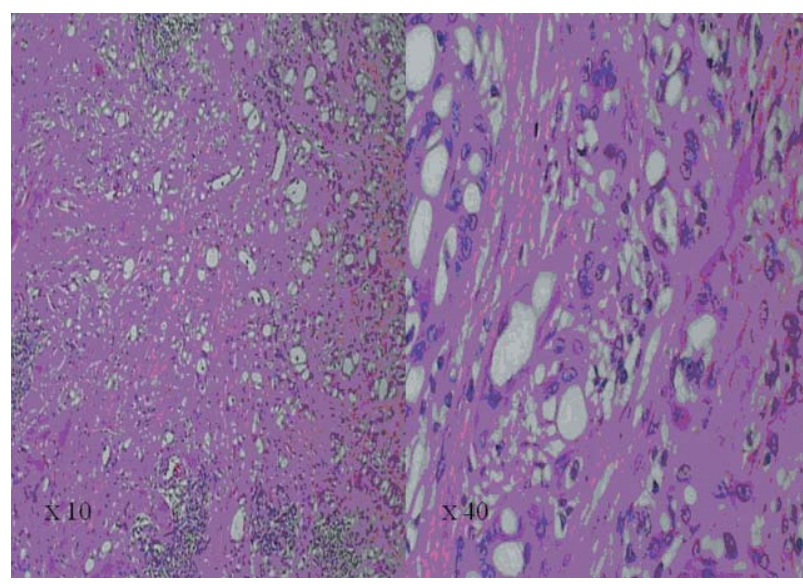

FIGURA 3. Células epiteliales con vacuolas de diverso tamaño en su citoplasma. lizar la resonancia nuclear magnética sin haberse determinado características típicas de estos tumores ni generalizarse su uso ${ }^{6}$.

Debido a la naturaleza benigna de este tumor y la presencia de un plano de clivaje habitual el tratamiento de elección es la escisión local ${ }^{7}$. Cursan con una correcta evolución y no se han registrado recurrencias de estos tumores en la literatura.

\section{REFERENCIAS}

1. Beccia DJ, Krane RJ, Olsson CA. Clinical management of nontesticular intrascrotal tumors. J Urol. 1976;116(4): 476-479.

2. Jerome P. Richie, Graeme S. Steele. Neoplasias del testiculo.En: Patrick C. Walsh. Campbell Urología. $8^{\underline{a}}$ ed. Buenos Aires: Medica Panamericana; 2004. p. 3186-3189.

3. Perez-Ordonez B, Srigley JR. Mesothelial lesions of the paratesticular region. Semin Diagn Pathol. 2000;17(4):294-306.

4. Khun MT, Maclennan GT. Benign neoplasms of the epididymis. J Urol. 2005; 174(2):723.

5. Alapont Pérez F.M, Gálvez Calderón J, Lemberg Lapaco PM, Varea Herrero J, Machin Hamalainen S. Adenomatoid tumor of the epididymis. Actas Urol Esp. 1999;23(7):613-616.

6. Akbar SA, Sayyed TA, Jafri SZ, Hasteh F, Neill JS. Multimodality imaging of paratesticular neoplasms and their rare mimics. Radiographics. 2003;23(6):1461-1476.

7. Williams SB, Han M, Jones R, Andrawis R. Adenomatoid tumor of the testes. Urology. 2004;63(4):779-781.

Correspondencia autora: Dra. P. Serrano Frago

Servicio de Urología. Hospital Universitario Miguel Servet

Po Isabel La Católica, 1-3. 50009 Zaragoza

Tel.: 976765500

E-mail autora: pserranof@comz.org Información artículo: Nota clínica

Trabajo recibido: noviembre 2005

Trabajo aceptado: abril 2006 